\title{
Lung Transplantation after Endoscopic Lung Volume Reduction
}

\author{
Thomas Fuehner $^{\mathrm{a}}$ Carolina Clajus $^{\mathrm{a}}$ Jan Fuge $^{c}$ Danny Jonigk ${ }^{d}$ \\ Tobias Welte $^{\mathrm{a}, \mathrm{c}}$ Axel Haverich ${ }^{\mathrm{b}}$ Mark Greer ${ }^{\mathrm{a}}$ Jens Gottlieb ${ }^{\mathrm{a}, \mathrm{c}}$ \\ Departments of a Respiratory Medicine and ${ }^{b}$ Cardiothoracic, Transplant and Vascular Surgery, Hannover Medical \\ School, ' Department of Internal Medicine, Hannover Medical School, Biomedical Research in Endstage and \\ Obstructive Lung Disease Hannover, German Center for Lung Research, and IInstitute of Pathology, Hannover \\ Medical School, Hannover, Germany
}

\section{Key Words}

Lung transplantation - Endoscopic lung volume reduction .

Airway colonization · Emphysema

\begin{abstract}
Background: Endoscopic lung volume reduction (ELVR) has become an established treatment option in selected patients with end-stage lung emphysema. ELVR, however, does not always prevent disease progression, and patients may inevitably be considered for lung transplantation. Objectives: Currently, limited data exist regarding the impact of preceding ELVR on lung transplantation outcomes. Methods: A retrospective, single-center analysis of lung transplantation (LTx) waiting list candidates, who had previously undergone ELVR for emphysema between 2010 and 2014, was performed. Outcomes were compared to matched (1:2) controls who underwent LTx for emphysema without previous ELVR. The 12-month survival after LTx represented the primary end point. Results: In total 23/693 (3\%) patients listed for LTx between January 2010 and May 2014 had undergone ELVR, of whom 20/23 (87\%) proceeded to LTx (ELVR group). Forty matched non-ELVR emphysema patients acted as controls. Bronchiectasis on CT prior to LTx was more evident in ELVR patients [11/20 (55\%) vs. 12/40 (30\%); $p=0.04]$ as well as airway colonization after LTx [10/20 (50\%) vs. 6/40
\end{abstract}

$(15 \%) ; p=0.004]$. Among ELVR patients, the most prevalent colonizing organism was Stenotrophomonas maltophilia (4/10 patients, $40 \%)$. No significant differences were observed in LTx waiting list time, duration of LTx procedure, ventilatory support, ICU stay after LTx or time to hospital discharge. One ELVR patient (5\%) died 189 days after LTx from pneumonia, compared to 1 non-ELVR patient (3\%) who died after 269 days $(p=0.61)$. Conclusions: Previous ELVR treatment was not associated with differing outcomes following LTx. Increased bacterial colonization rates were evident and warrant further investigation.

() 2015 S. Karger AG, Basel

\section{Introduction}

Lung transplantation (LTx) is an established therapy for selected patients with end-stage lung disease [1]. Common conditions requiring LTx are chronic obstructive pulmonary disease (COPD), idiopathic pulmonary fibrosis, cystic fibrosis and pulmonary arterial hypertension [2]. According to current International Society for Heart and Lung Transplantation registry data, COPD represents the leading indication worldwide, accounting for $40 \%$ of procedures. In Germany, the pooled prevalence of COPD is 7.6\% [3-5] with advanced COPD

\section{KARGER 125}

(c) 2015 S. Karger AG, Basel

0025-7931/15/0903-0243\$39.50/0 
(GOLDIII+) accounting for 3.2\% [3]. Emphysema is a fundamental component of COPD and is characterized by airspace enlargement, caused by extensive destruction of the alveolar walls, resulting in debilitating hyperinflation. Emphysema is often attributed to smoking, with $\alpha_{1^{-}}$ antitrypsin deficiency being responsible in about $6 \%$ of cases [2]. Medical treatment consists primarily of bronchodilators, supplemental oxygen therapy and in advanced cases noninvasive ventilation. Most treatment options improve quality of life but have limited impact on survival.

As an attempt to alleviate hyperinflation, lung volume reduction surgery was proposed as a possible solution some 20 years ago, with acceptable results [6]. This approach employed a buttressed staple excision of hyperinflated, nonfunctioning lung segments, allowing improved function of the remaining lung. Improved exercise ability, quality of life and survival were reported in highly selected candidates (National Emphysema Treatment Trial) [7]. The reported morbidity and an attributable mortality were however considerable at $5 \%$.

In recent years, endoscopic lung volume reduction (ELVR) has emerged in various guises as a less invasive alternative to surgery in these patients $[8,9]$. Deployment of one-way valves remains the most popular approach [10-12], with randomized trials reporting benefit in terms of lung function, exercise capacity and potentially survival in highly selected patients with heterogeneous disease and an intact lobar fissure [11-13]. Other ELVR, nonblocking methods include use of sealants [14], thermal therapy and endobronchial coils, which have been the subject of small randomized trials and one multicenter cohort study, which could show improvements in life quality, exercise ability and lung function [15-18]. Endobronchial coiling attempts to distort segmental airways, restore the tethering effect on small airways, and compress emphysematous lung parenchyma. Another ELVR approach is vapor delivered in targeted areas. Thermal therapy relies upon targeted delivery of hot vapor in an attempt to destroy areas of remodeled lung [18]. No controlled studies regarding this technical approach have been published to date.

Despite the popularity of ELVR, the number of studies remains small. Further evaluation of the value in treating severe hyperinflated emphysema is necessary and the subject of larger ongoing studies. Limited data relating to the potential usefulness of previous ELVR in LTx recipients, with analysis focusing exclusively on the pre-LTx course, exist [19].

\section{Methods}

A single-center retrospective analysis was performed. Hannover Medical School has a high-volume lung transplant program, routinely performing more than 130 procedures per year. Currently, more than 850 patients actively participate in outpatient LTx follow-up.

Emphysema patients referred for LTx evaluation between January 2010 and May 2014 were reviewed, with those proceeding to transplantation, having previously undergone ELVR, being included. From the remaining emphysema LTx recipients who had not undergone ELVR, a control group matched 1:2 for gender, age and $\alpha_{1}$-antitrypsin status was generated.

All potential LTx candidates referred to our center undergo multidisciplinary assessment involving surgeons, pulmonologists and psychologists. Prerequisite investigations include extensive laboratory testing to exclude other end-organ disease, sputum samples to assess colonization, a CT of the thorax and vascular imaging to plan perioperative management. Once listed for LTx, candidates were closely monitored at our outpatient clinic. Since December 2011 the lung allocation score (LAS) has been implemented in Germany [20,21], with relevant data collection having previously been commenced at our center in January 2010. Final LAS values and $\triangle$ LAS (LAS last before transplantation - LAS upon listing) were calculated.

Patient and graft survival, duration of transplant procedure, length of ICU and overall hospital stay, airway colonization, quality of life, 6-min walk distance and infection episodes after LTx were analyzed [22]. Quality of life was measured by the 5-dimension EuroQol score [23], from which the visual analog scale was assessed.

After LTx infections requiring hospitalization, infection episodes (detection of a new pathogen followed by anti-infective treatment) and rejection episodes were analyzed.

Our study adhered to ethical guidelines described in the 1975 Declaration of Helsinki. All patients provided informed consent prior to transplantation, using a standardized consent form approved by the local ethics committee, which allowed use of their data for scientific purposes in retrospective analysis.

\section{Respiratory Sampling}

Bronchoscopy was not routinely performed as part of transplant evaluation. Sputum samples (if possible) were analyzed in each listed candidate before transplantation, and cultures were routinely taken from the recipient bronchi at the time of native lung removal. Following transplantation all patients participated in our long-term surveillance program, which included regular bronchoalveolar lavage and transbronchial biopsies. Colonization was defined as any repeated or intermittent isolation of typical respiratory pathogens [24].

\section{CT Analysis}

Three lung sections were analyzed representing the lower, middle and upper lung, identified by taking the 75th, 50th and 25th percentile images from the entire number of images in the lung sequence, with the 25th percentile taken to represent the upper lobe. On these reference images, evidence of atelectasis or bronchiectasis was assessed, with the latter being graduated using a 'none' (0), 'mild' (1) and 'severe' (2) scale for each individual lung. Reviewers were allowed to examine adjacent CT slices to verify changes. Bronchiectasis was defined as a total score (max. 12) of 3 and more. 
Fig. 1. Flowchart. DLTx $=$ Double lung

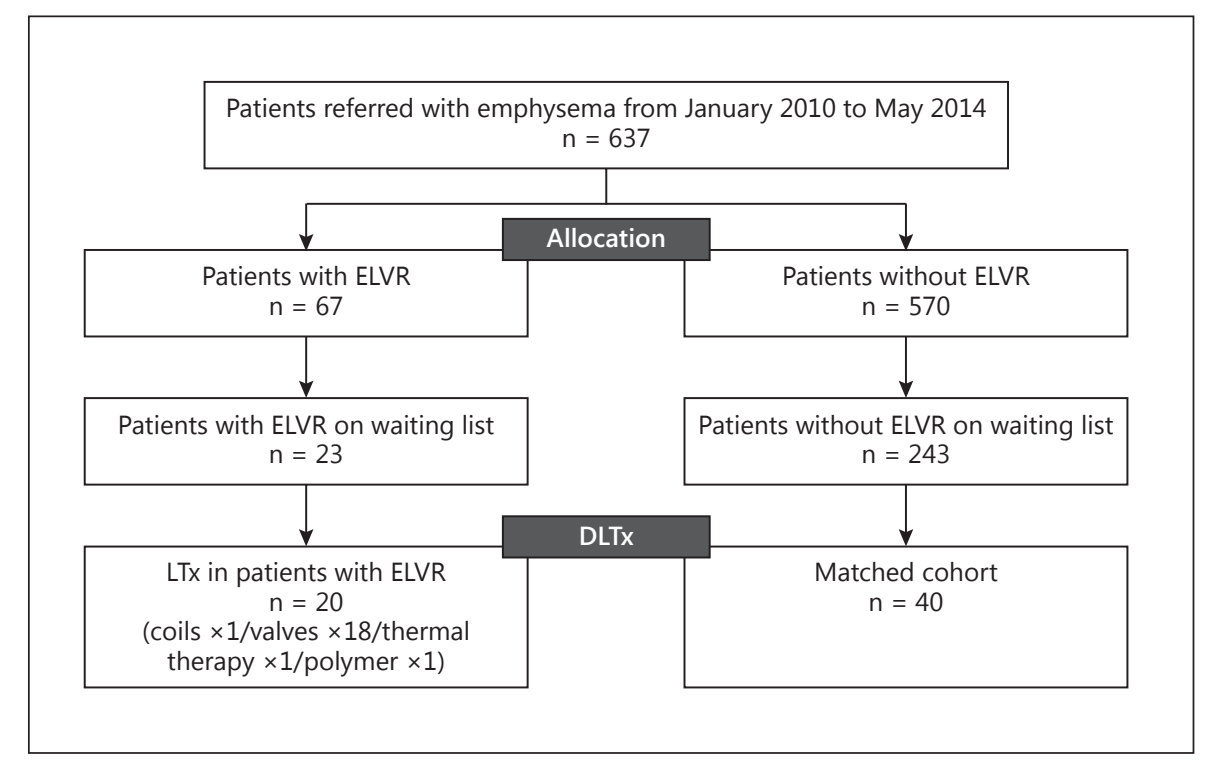
transplantation.

\section{Histopathology}

All lungs underwent routine histopathological workup following explantation. The formalin-fixed, paraffin-embedded samples were retrieved from the archives of the Institute of Pathology (Hannover Medical School) and re-evaluated by an experienced pulmonary pathologist.

\section{Statistics}

Statistical analysis was performed with SPSS 22.0 (SPSS, Chicago, Ill., USA): continuous variables are presented as median and interquartiles. Categorical variables were analyzed by the $\chi^{2}$ test. Medians were compared with Fisher's exact test, nonparametric variables with the Mann-Whitney U test. Kaplan-Meier statistics were used to estimate survival rates with statistical significance assessed by the log rank test. For all analyses, $\mathrm{p}$ values less than 0.05 were considered statistically significant.

\section{Results}

\section{Waiting List and Referrals}

During the study period, 1,562 patients were referred for LTx. Of these, 637 had emphysema as underlying diagnosis $(40.8 \%)$ with 109 having proven $\alpha_{1}$-antitrypsin deficiency (17.1\%). The number of referrals with previous ELVR has been steadily increasing in recent years: in 2010 $\mathrm{n}=4 / 203(2 \%)$, in $2011 \mathrm{n}=13 / 135(10 \%)$, in $2012 \mathrm{n}=$ $15 / 105(15 \%)$, in $2013 \mathrm{n}=17 / 102(17 \%)$ and in $2014 \mathrm{n}=$ $18 / 92$ (20\%). Overall $23 / 67$ patients (34\% of referrals) with previous ELVR were listed for LTx.

Since 2010, 23 (4\%) patients died awaiting LTx. None of these patients had previously undergone ELVR.

\section{Transplantations}

Between 2010 and 2014, 651 LTx were performed at our center, including 20/23 (87\%) of the ELVR patients listed (fig. 1). Patient characteristics are displayed in table 1. In all patients, ELVR had been performed at their local referring hospital.

All patients included in the analysis underwent double LTx. Of the 20 ELVR patients transplanted, 18 had received ELVR with valves (right lower lobe: 3 , right upper lobe: 6 , left upper lobe: 12 , right lower lobe: 2 and bilateral upper lobes: 3$)$. In 1 of these valve patients (1/18) thermal therapy (right lower lobe) followed after removal of prior valves. A single patient received coils (combined upper lobes), and 1 further patient received polymer sealant (right lower lobe). The median interval between ELVR and LTx was 2 years. No difference in the last LAS score or exacerbation episodes before transplantation were noted between groups (table 1).

\section{CT Analysis}

Of the 18 patients who underwent ELVR with valves, these were visible on CT in 16 cases (89\%). In 6/16 (38\%) of these, atelectasis of the target lobe was evident. Bronchiectasis was more prevalent in the ELVR group (11/20, $55 \%)$ compared to the control group (12/40,30\%; p = 0.04 ; table 1). Although bronchiectasis was identified in nontreated lobes in the majority of patients $(13 / 18,82 \%)$, 5/18 (28\%) patients exhibited bronchiectasis in ELVRtreated lobes (fig. 2). 
Table 1. Baseline

\begin{tabular}{|c|c|c|c|}
\hline & $\begin{array}{l}\text { ELVR group } \\
(\mathrm{n}=20)\end{array}$ & $\begin{array}{l}\text { Control group } \\
(\mathrm{n}=40)\end{array}$ & $\mathrm{p}$ \\
\hline Age, years & $56[51-59]$ & $55[52-58]$ & 0.873 \\
\hline Gender female & $10(50)$ & $20(50)$ & 1.0 \\
\hline BMI & $20[17-24]$ & $24[19-26]$ & 0.07 \\
\hline$\alpha_{1}$-Antitrypsin deficiency yes & $5(25)$ & $6(15)$ & 0.48 \\
\hline PAPm 25 mm Hg & $3(15)$ & $0(0)$ & 0.33 \\
\hline Bronchiectasis score $>2$ & $11(55)$ & $12(30)$ & 0.04 \\
\hline \multicolumn{4}{|l|}{ Before LTx } \\
\hline First LAS score & $31[29-33]$ & $32[31-33]$ & 0.55 \\
\hline Last LAS score & $33[32-34]$ & $32[31-33]$ & 0.8 \\
\hline$\Delta$ LAS score & $0.5[-1$ to 2$]$ & $1[0-2]$ & 0.56 \\
\hline Days on waiting list & $43[8-110]$ & $120[28-353]$ & 0.18 \\
\hline QoL & $7.6[6.3-8.4]$ & $7.3[6.3-8.3]$ & 0.59 \\
\hline Days between ELVR and LTx & $734[463-1,246]$ & - & - \\
\hline Exacerbation with hospitalization 12 months & $1(0-2)$ & $1(0-2)$ & 0.73 \\
\hline Exacerbation, ABX 12 months & $2[1-2.75]$ & $1[1-2]$ & 0.34 \\
\hline $6 \mathrm{MWT}$ & $276[166-305]$ & $167[105-308]$ & 0.09 \\
\hline $6 \mathrm{MWT}$ predicted $\%$ & $38[14-45]$ & $50[16-58]$ & 0.47 \\
\hline Long-term oxygen therapy & $19(95)$ & $40(100)$ & 0.15 \\
\hline Oxygen, $1 / \mathrm{min}$ & $3[3-3.75]$ & $3[2-3]$ & 0.45 \\
\hline Noninvasive ventilation & $13(65)$ & $20(50)$ & 0.27 \\
\hline
\end{tabular}

$\mathrm{BMI}=$ Body mass index $\mathrm{PAPm}=$ mean pulmonary artery pressure; $\mathrm{QoL}=$ quality of life; $\mathrm{ABX}=$ antibiotic; $6 \mathrm{MWT}=6$ - $\mathrm{min}$ walk distance in meters, by Enright [22]. Values are medians with interquartile ranges in square brackets and numbers with percentages in parentheses.

Table 2. Outcome (12 months after LTx)

\begin{tabular}{lccl}
\hline & $\begin{array}{l}\text { ELVR group } \\
(\mathrm{n}=20)\end{array}$ & $\begin{array}{l}\text { Control group } \\
(\mathrm{n}=40)\end{array}$ & $\mathrm{p}$ \\
\hline Revision & $1(5)$ & $2(5)$ & 1.0 \\
Operation time, min & $252[236-299]$ & $260[248-308]$ & 0.15 \\
Respirator days & $1[1-1]$ & $1[1-1]$ & 1.0 \\
ICU days & $2[1-2]$ & $2[1-2]$ & 0.54 \\
Discharge from hospital, & & & \\
days & $21[19-26]$ & $24[21-26]$ & 0.59 \\
6MWT at discharge & $397[335-418]$ & $380[307-435]$ & 0.54 \\
6MWT predicted\% & $122[94-129]$ & $118[110-129]$ & 0.68 \\
$\Delta 6$ MWT predicted\% & $89[75-99]$ & $71[58-104]$ & 0.78 \\
QoL & $8[5.6-9]$ & $7.5[5-9]$ & 0.61 \\
Infection episodes after LTx & $1[0-1]$ & $1[0-1]$ & 0.17 \\
Rejection episodes after & & & \\
LTx (biopsy-proven A1+) & $1[0-1]$ & $1[0-1]$ & 0.44 \\
Hospitalization after LTx & $0[0-2]$ & $1[0-2]$ & 0.69 \\
Death at 12 months & $1(5)$ & $1(2.5)$ & 0.61 \\
\hline
\end{tabular}

For explanations, see table 1.

\section{Outcome}

No significant differences were observed between ELVR patients and their matched controls with regard to the principal clinical outcome parameters, e.g. transplant duration, days on ventilator support, ICU stay, length of hospital stay or 12-month graft survival (table 2). In both groups, no patients underwent re-do transplantation during follow-up. In the ELVR group, 1 patient died after virus pneumonia and graft dysfunction 189 days after LTx. In the control group, 1 patient died after 279 days due to restrictive allograft dysfunction. There was no survival difference between groups (table 2). There was no difference in terms of 6-meter walk distance, quality of life, infection or rejection episodes during the 12-month follow-up.

\section{Histopathology}

All lung explants were re-evaluated, and findings were correlated with the radiological results lined out above. All specimens showed severe emphysema with prominent bronchiectasis in some, correlating with CT findings. 


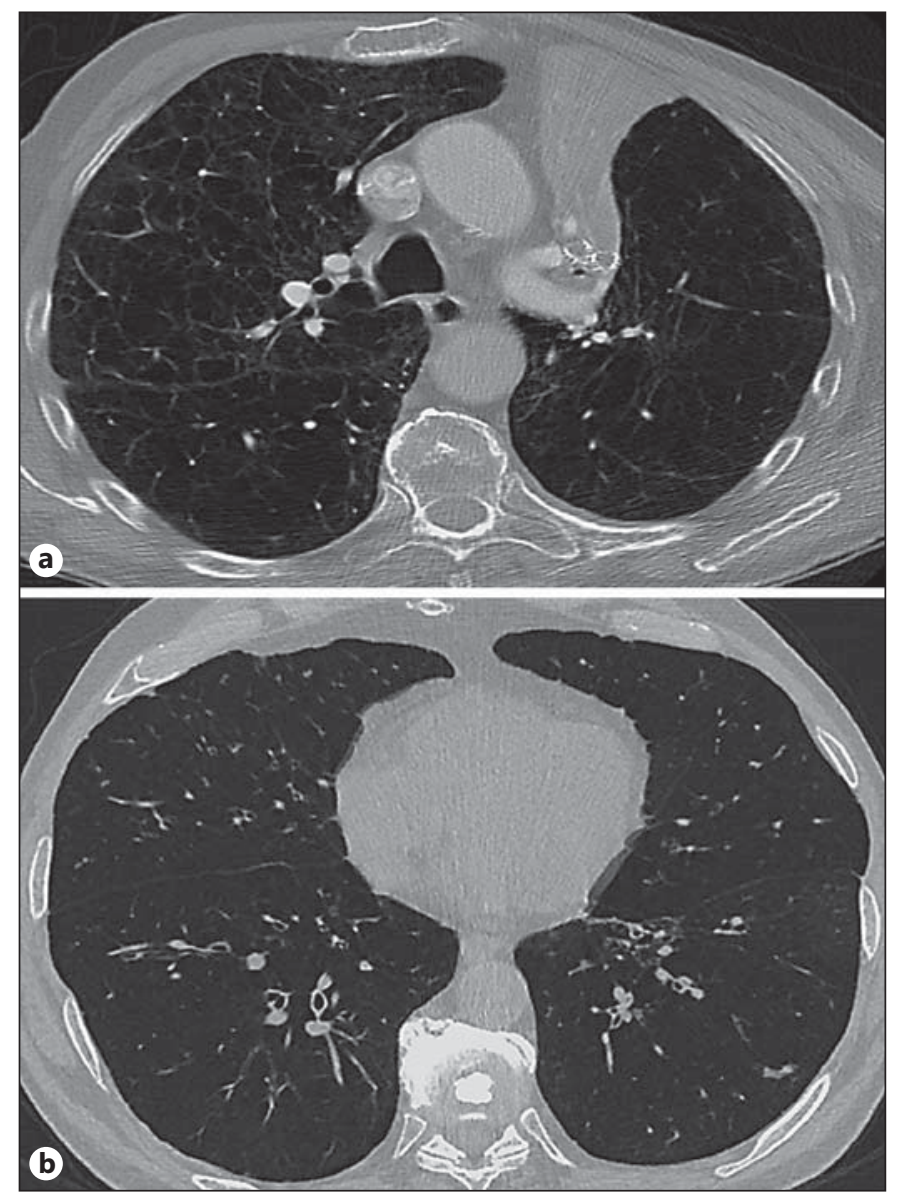

\section{Microbiology Results}

Sputum cultures were available in $42 / 60(70 \%)$ patients (ELVR 16/20). Intraoperative swabs taken from the recipient bronchus were available for all patients. No differences existed between groups regarding airway colonization rates $(\mathrm{p}=0.13)$ prior to transplantation (table 3$)$. After LTx, airway colonization rates were higher among ELVR patients compared to controls [10/20 (50\%) vs. $6 / 40(15 \%) ; \mathrm{p}=0.004]$. The most common organism was Stenotrophomonas maltophilia, being identified in $4 / 10$ (40\%) ELVR patients. Other organisms isolated are displayed in table 3 .

The single patient who received coils was colonized with Acinetobacter baumannii after LTx. The other nonvalve patients (polymer sealant and thermal therapy) demonstrated no colonization before or after LTx.

Bronchiectasis (before LTx) was evident in 5/11 (45\%) of ELVR patients with known airway colonization (after LTx). These patients were colonized with: $3 \times S$. maltophilia, $1 \times$ oxacillin-resistant Staphylococcus aureus, $1 \times A$.

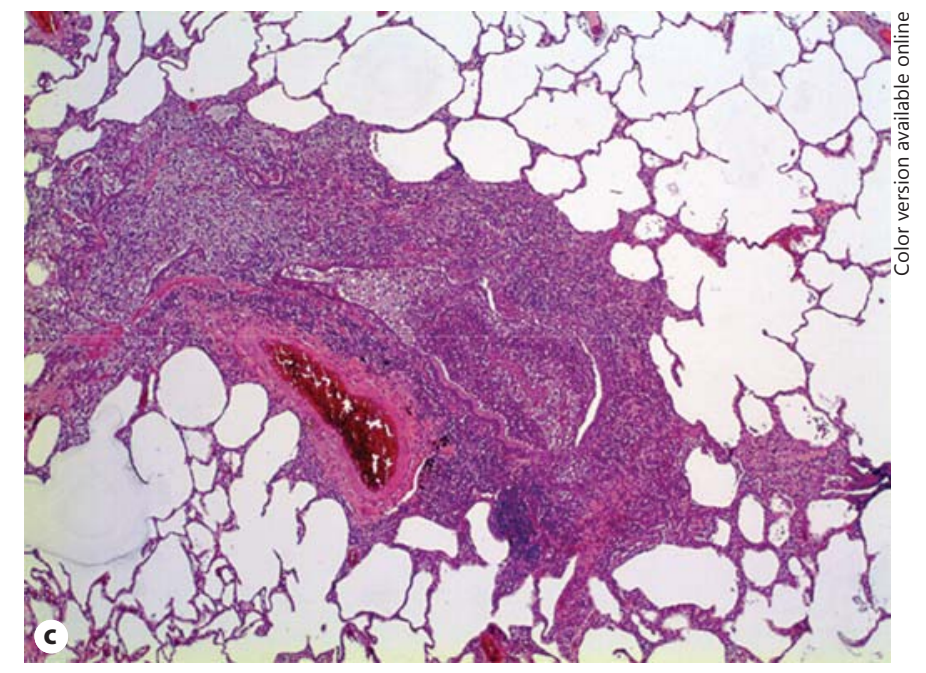

Fig. 2. a, b Patient with valves and bronchiectasis. c Ectasia of the bronchus with prominent inflammation and fibrosis. Original magnification $\times 20$.

baumannii. None of the control group with evidence of bronchiectasis $(12 / 40,30 \%$; table 1$)$ was colonized $(\mathrm{p}=$ 0.008 ; table 3$)$.

\section{Discussion}

To our knowledge, this is the largest study assessing the impact of previous ELVR in emphysema patients proceeding to LTx. Previous ELVR treatment was not associated with significant differences in outcome, but increased rates of airway colonization were observed.

The St. Louis group has previously reported on LTx following lung volume reduction surgery [25]. In the largest series involving 36 patients, Backhus et al. [26] identified both a longer transplantation duration and greater length of hospital stay. Thirty-day mortality and major morbidity rates were unaffected.

EVLR after LTx has been reported by Perch et al. [27], who inserted endobronchial valves in hyperinflated na- 
Table 3. Airway colonization

\begin{tabular}{llll}
\hline & $\begin{array}{l}\text { ELVR } \\
\text { group } \\
(\mathrm{n}=20)\end{array}$ & $\begin{array}{l}\text { Control } \\
\text { group } \\
(\mathrm{n}=40)\end{array}$ & $\mathrm{p}$ \\
\hline Any colonization before LTx & $5(25)$ & $4(10)$ & 0.13 \\
Stenotrophomonas maltophilia & 1 & 1 & \\
ORSA & 0 & 1 & \\
MSSA & 1 & 1 & \\
Escherichia coli & 1 & 1 & \\
Proteus mirabilis & 1 & 0 & \\
Enterobacter aerogenes & 1 & 0 & \\
Any colonization after LTx & $10(50)$ & $6(15)$ & 0.004 \\
Stenotrophomonas maltophilia & 4 & 1 & \\
Pseudomonas aeruginosa & 1 & 1 & \\
ORSA & 1 & 1 & \\
MSSA & 1 & 1 & \\
Klebsiella pneumoniae & 1 & 1 & \\
Escherichia coli & 1 & 0 & \\
Acinetobacter baumannii & 1 & 0 & \\
Proteus mirabilis & 0 & 1 & \\
Different organism colonization & & & \\
(compared to pre-LTx n $=5)$ & $7(35)$ & $5(13)$ & 0.04 \\
Bronchiectasis before LTx & & & \\
(CT score $>$ 2) & 11 & 12 & \\
Any colonization before LTx & $3 / 11(27)$ & $1 / 12(8)$ & 0.23 \\
Any colonization after LTx & $5 / 11(45)$ & $0 / 12(0)$ & 0.008 \\
\hline & & & \\
\hline
\end{tabular}

ORSA = Oxacillin-resistant Staphylococcus aureus; MSSA = methicillin-sensitive Staphylococcus aureus. Values are numbers with percentages in parentheses.

tive lungs in 14 patients subsequent to single-lung transplantation for emphysema. Two patients suffered from pneumothoraces, 1 developed pneumonia at the time of valve placement, and another developed an infection in the subsequent days. The authors concluded that endobronchial valves improved the clinical condition in the majority of patients, and that acceptable safety could be demonstrated.

To our knowledge, data regarding LTx after ELVR are limited to a case series of patients treated with sealant [19]. Fruchter et al. [19] reported on 5 patients, focusing on the histological effects of ELVR with sealant; however, the post-LTx course was not described.

In our series, we could not identify any differences in regard to transplant survival as a result of ELVR treatment, a result in keeping with most recent publications about LTx because of emphysema, short-term survival with or without previous ELVR. This information complements the safety profile of ELVR treatment and indicates its potential role as bridging strategy to LTx.
The majority of ELVR patients in this series received endobronchial valves $(n=18)$, of which approximately one third were evident on CT, and atelectasis of the target lobe could be identified. Atelectasis after valve implementation is considered a predictor for clinical benefit from ELVR. Atelectasis itself does not appear to influence subsequent LTx outcome [12]. The low rate of atelectasis indicates a minority of ELVR nonresponders.

In this series, only single patients underwent coiling, polymer sealant or water vapor treatments, which limits the transferability of all techniques. At least treatment with endobronchial coils has recently been shown to be a promising treatment in emphysema patients in a not yet well-defined subgroup of patients [16]. Further evaluation of this treatment strategy and its impact on LTx needs to be evaluated.

Previous studies have shown that de novo airway colonization of the lung allograft with Gram-negative bacteria is associated with subsequent chronic lung allograft dysfunction $[24,28,29]$. Other studies have demonstrated that donor colonization impairs LTx outcomes [30], with the impact of donor-to-host transmission being previously described [31]. In our study, airway colonization was evident in the bronchoalveolar lavage fluid of $50 \%$ of EVLR patients after LTx, much higher than would be expected or indeed observed among non-ELVR patients. Gram-negative bacteria predominated, with S. maltophilia attracting particular attention (table 3 ). The majority of ELVR patients had received valves, which potentially increase the risk of colonization, as airway foreign bodies may result in biofilm formation, impeding ciliary clearance.

Potential confounders accounting for airway colonization aside from ELVR may include previous antibiotic treatment in both the recipient and donor, as well as donor transmission. Nevertheless, bronchiectasis was more frequently seen in ELVR patients, although no difference in the incidence of airway colonization existed prior to transplantation between patient groups. CT scans prior to ELVR treatment were unavailable for retrospective evaluation, so the true prevalence of bronchiectasis prior to ELVR or even the possibility of ELVR inducing bronchiectasis remains unclear. Reports associating ELVR with an increased incidence of infective exacerbations as a potential risk factor for pathological colonization do exist [12]. Fruchter et al. [32] have recently published a case series of bacterial colonization in ELVR patients that may potentially explain the higher incidence of bronchiectasis in these. Noncystic fibrosis bronchiectasis is a further, separate risk factor for Gram-negative bacteria coloniza- 
tion [33] and may possibly overlap with a clinical diagnosis of COPD. Important differences exist in the ability to screen for colonization before and after LTx, with reliance on differing sources needing to be considered (sputum and bronchus swab vs. bronchoalveolar lavage after LTx).

This work has several limitations. The sample size is small and reflects a single-center experience. All reported data have been evaluated retrospectively, and minimal data exists regarding nonvalve ELVR. Patient selection for LTx after ELVR creates inherent negative bias towards ELVR nonresponders within our cohort. Long-term data, in particular the development of chronic lung allograft dysfunction and the potentially negative impact of higher colonization rates, are lacking. The safety profile of all ELVR techniques and their impact on LTx outcome require further studies.

In conclusion, ELVR treatment in LTx candidates does not appear to influence early outcomes. ELVR ap- pears potentially associated with increased rates of airway colonization and bronchiectasis before LTx, which may subsequently impact negatively on long-term survival after LTx. Further research into long-term outcomes is therefore required.

\section{Acknowledgment}

The authors thank Paul Borchert for his technical support.

\section{Financial Disclosure and Conflicts of Interest}

This work is supported by a grant from the Deutsche Forschungsgemeinschaft (DFG, grant 743/2-1 to Danny Jonigk) and by the German Center for Lung Research (Deutsches Zentrum für Lungenforschung). The authors have no conflicts of interest to disclose.

\section{References}

1 Lynch JP 3rd, Saggar R, Weigt SS, Ross DJ, Belperio JA: Overview of lung transplantation and criteria for selection of candidates. Semin Respir Crit Care Med 2006;27:441-469.

- 2 Yusen RD, Christie JD, Edwards LB, Kucheryavaya AY, Benden C, Dipchand AI, Dobbels F, Kirk R, Lund LH, Rahmel AO, Stehlik J; International Society for Heart and Lung Transplantation: The Registry of the International Society for Heart and Lung Transplantation. Thirtieth Adult Lung and Heart-Lung Transplant Report - 2013, focus theme: age. J Heart Lung Transplant 2013;32:965-978.

-3 Schiller JS, Lucas JW, Ward BW, Peregoy JA: Summary health statistics for US adults: National Health Interview Survey, 2010. Vital Health Stat 10 2012;252:1-207.

4 Halbert RJ, Natoli JL, Gano A, Badamgarav E, Buist AS, Mannino DM: Global burden of COPD: systematic review and meta-analysis. Eur Respir J 2006;28:523-532.

5 Burney P, Jithoo A, Kato B, Janson C, Mannino D, Nizankowska-Mogilnicka E, Studnicka M, Tan W, Bateman E, Koçabas A, Vollmer WM, Gislason T, Marks G, Koul PA, Harrabi I, Gnatiuc L, Buist S; Burden of Obstructive Lung Disease (BOLD) Study: Chronic obstructive pulmonary disease mortality and prevalence: the associations with smoking and poverty - a BOLD analysis. Tho$\operatorname{rax} 2014 ; 69: 465-473$.

-6 Brantigan OC, Mueller E: Surgical treatment of pulmonary emphysema. Am Surg 1957;23: 789-804.
-7 Fishman A, Martinez F, Naunheim K, Piantadosi S, Wise R, Ries A, Weinmann G, Wood DE; National Emphysema Treatment Trial Research Group: A randomized trial comparing lung-volume-reduction surgery with medical therapy for severe emphysema. N Engl J Med 2003;348:2059-2073.

8 Van Raemdonck D, Ninane V: Lung volume reduction for severe emphysema: do we need a scalpel or a scope? Eur Respir Rev 2012;19: 242-247.

-9 Taneja A: Bronchoscopic interventions in the management of chronic obstructive pulmonary disease. Curr Opin Pulm Med 2013;19: 145-151.

10 Shah PL, Herth FJ: Current status of bronchoscopic lung volume reduction with endobronchial valves. Thorax 2014;69:280-286.

11 Sciurba FC, Ernst A, Herth FJ, Strange C, Criner GJ, Marquette CH, Kovitz KL, Chiacchierini RP, Goldin J, McLennan G; VENT Study Research Group: A randomized study of endobronchial valves for advanced emphysema. N Engl J Med 2010;363:1233-1244.

12 Herth FJ, Noppen M, Valipour A, et al: Efficacy predictors of lung volume reduction with Zephyr valves in a European cohort. Eur Respir J 2012;39:1334-1342.

13 Ninane V, Geltner C, Bezzi M, et al: Multicentre European study for the treatment of advanced emphysema with bronchial valves. Eur Respir J 2012;39:1319-1325.

14 Kramer MR, Refaely Y, Maimon N, Rosengarten D, Fruchter O: Two-year follow-up in patients treated with emphysematous lung sealant for advanced emphysema. Chest 2013; 144:1677-1680.

15 Shah PL, Zoumot Z, Singh S, Bicknell SR, Ross ET, Quiring J, Hopkinson NS, Kemp SV; RESET Trial Study Group: Endobronchial coils for the treatment of severe emphysema with hyperinflation (RESET): a randomised controlled trial. Lancet Respir Med 2013;1:233240.

16 Deslee G, Klooster K, Hetzel M, Stanzel F, Kessler R, Marquette CH, Witt C, Blaas S, Gesierich W, Herth FJ, Hetzel J, van Rikxoort EM, Slebos DJ: Lung volume reduction coil treatment for patients with severe emphysema: a European multicentre trial. Thorax 2014;69:980-986.

17 Slebos DJ, Klooster K, Ernst A, et al: Bronchoscopic lung volume reduction coil treatment of patients with severe heterogeneous emphysema. Chest 2012;142:574-582.

-18 Snell G, Herth FJ, Hopkins P, Baker KM, Witt C, Gotfried MH, Valipour A, Wagner M, Stanzel F, Egan JJ, Kesten S, Ernst A: Bronchoscopic thermal vapour ablation therapy in the management of heterogeneous emphysema. Eur Respir J 2012;39: 1326-1333.

19 Fruchter O, Fridel L, Kramer MR: The pathological features of bronchoscopic lung volume reduction using sealant treatment assessed in lung explants of patients who underwent lung transplantation. Respiration 2013;86:143144 
20 Strüber M, Reichenspurner H: Die Einführung des Lungenallokations-Scores für die Lungentransplantation in Deutschland. Dtsch Ärztebl 2011;108:A-2424.

21 Gottlieb J: Lung transplantation (in German). Dtsch Med Wochenschr 2013;138:15851588.

22 Enright PL: The six-minute walk test. Respir Care 2003;48:783-785.

23 Anyanwu AC, McGuire A, Rogers CA, Murday AJ: Assessment of quality of life in lung transplantation using a simple generic tool. Thorax 2001;56:218-222.

24 Gottlieb J, Mattner F, Weissbrodt H, Dierich M, Fuehner T, Strueber M, Simon A, Welte T: Impact of graft colonization with Gram-negative bacteria after lung transplantation on the development of bronchiolitis obliterans syndrome in recipients with cystic fibrosis. Respir Med 2009;103:743-749.

25 Meyers BF, Patterson GA: Lung transplantation: current status and future prospects. World J Surg 1999;23:1156-1162.
26 Backhus L, Sargent J, Cheng A, Zeliadt S, Wood D, Mulligan M: Outcomes in lung transplantation after previous lung volume reduction surgery in a contemporary cohort. Thorac Cardiovasc Surg 2014;147:16781683.

27 Perch M, Riise GC, Hogarth K, Musani AI, Springmeyer SC, Gonzalez X, Iversen M: Endoscopic treatment of native lung hyperinflation using endobronchial valves in singlelung transplant patients: a multinational experience. Clin Respir J 2015;9:104-110.

28 Vos R, Vanaudenaerde BM, De Vleeschauwer SI, Van Raemdonck DE, Dupont LJ, Verleden GM: De novo or persistent pseudomonal airway colonization after lung transplantation: importance for bronchiolitis obliterans syndrome? Transplantation 2008;86:624-625.

29 Botha P, Archer L, Anderson RL, Lordan J, Dark JH, Corris PA, Gould K, Fisher AJ: Pseudomonas aeruginosa colonization of the allograft after lung transplantation and the risk of bronchiolitis obliterans syndrome 2008 ; 85 : 771-774.
30 Avlonitis VS, Krause A, Luzzi L, Powell H, Phillips JA, Corris PA, Gould FK, Dark JH: Bacterial colonization of the donor lower airways is a predictor of poor outcome in lung transplantation. Eur J Cardiothorac Surg 2003;24:601-607.

31 Ruiz I, Gavaldà J, Monforte V, Len O, Román A, Bravo C, Ferrer A, Tenorio L, Román F, Maestre J, Molina I, Morell F, Pahissa A: Donor-to-host transmission of bacterial and fungal infections in lung transplantation. Am J Transplant 2006;6:178-182.

32 Fruchter O, Rosengarten D, Goldberg E, BenZvi H, Tor R, Kramer MR: Airway bacterial colonization and serum C-reactive protein are associated with chronic obstructive pulmonary disease exacerbation following bronchoscopic lung volume reduction. Clin Respir J, Epub ahead of print.

33 McShane PJ, Naureckas ET, Tino G, Strek ME: Non-cystic fibrosis bronchiectasis. Am J Respir Crit Care Med 2013;188:647-656.

\section{Erratum}

Table 5 in the paper by Confalonieri $\mathrm{M}$ et al. entitled 'Opening of a respiratory intermediate care unit in a general hospital: impact on mortality and other outcomes' [Respiration 2015;90:235-242] should read:

Table 5. Management attitude and treatment timing in a sample of matched patients with ARF admitted in different hospital setting

\begin{tabular}{lcrrr}
\hline & RICU & $\begin{array}{l}\text { Emergency } \\
\text { unit }\end{array}$ & $\begin{array}{l}\text { Internal } \\
\text { medicine wards }\end{array}$ & $\mathrm{p}$ \\
\hline Median time to second blood gas check, h & $1.56(0.4)$ & $4.26(3.4)$ & $17.1(10.9)$ & $<0.0001$ \\
Mean time to antibiotics initiation, h & $0.84(0.3)$ & $1.63(1.6)$ & $2.2(2.12)$ & $<0.0001$ \\
Median time to mechanical ventilation, days & $0.3(0.6)$ & $0.7(0.7)$ & $4.8(3.2)$ & 0.0001 \\
Use of NIV, n (\%) & $42(70.0)$ & $27(46.5)$ & $12(19.3)$ & 0.0001 \\
Use of corticosteroids, n (\%) & $58(96.6)$ & $46(79.3)$ & $39(62.9)$ & 0.0012 \\
Use of chest physiotherapy, n (\%) & $43(71.6)$ & $11(18.9)$ & $6(9.6)$ & 0.0001 \\
\hline
\end{tabular}

Data in parentheses are interquartile ranges or standard deviations unless otherwise indicated. 